\title{
Improve Teaching Quality of Machine Design Course by Comprehensive Application of Multiple Methods
}

\author{
Fang Tian \\ School of Mechanic Engineering \\ Shenyang University of Technology \\ Shenyang,China \\ E-mail: sytf2003@126.com
}

\begin{abstract}
The characteristics of machine design course are defined as weak in system and strong on practicalness. So improving effect of teaching should be realized by focusing on teaching methods. The paper starts with analysis on the structure and feature of course. The appropriate teaching methods are figured out through the lecture about basic theory, experiment course about test of typical parts and design course about capacity training. Some important issues and solutions in main teaching program of mechanical design are putted forward in aspects of methods and means.
\end{abstract}

\section{Keywords-machine design; teaching method; course reform}

\section{INTRODUCTION}

Machine design course is a main foundation course which can train students to be more competent in mechanical design. The course content includes discussions about basic knowledge of mechanical design, fundamental viewpoints, procedure of design. And we can learn design methods of four typical kinds of mechanical components(connect, mechanical drive, shafting and so on) from different aspects such as working condition, analysis of main failure form, design of calculation criterion, calculation of main parameters, methods of correction and design of typical construction. Integrally, we can learn basic knowledge about mechanical system design. However, machine design course dose not only link to theoretical knowledge, but also with strong practicality. And even more, because of plentiful content and poor systematicness, it is very difficult for students to understand and catch the meaning and the result of teaching will be bad, so the quality of teaching will be no guarantee. But this course is one of foundation courses in the major of mechanics. So, it is important for students to have a firm grasp and get handy with these knowledge which will make it easy to study other courses in mechanics. Analysing the teaching methods of machine design course is significant to solute those problems above. In order to promote teaching effect of this course and reach the teaching aims, we can improve mechanical design teaching in several aspects as follow through years of teaching practice.

\section{SUMMARIZING THE TEACHING LAW AND IMPROVING THE TEACHING METHOD}

Mechanical design primarily focuses on those universal parts contributed in different kinds of machines. According to the function, universal parts can be divided into categories.
They are connecting piece, transmission parts, shafting parts and other parts. Connecting piece includes screw joint, keyed joint, spline joint, pin joint, riveting, welding, shaft\&hub connection, interference fit connection and so on. Transmission parts is mean to those parts which transmit movement and driving force, and including screw drive, belt drive, chain drive, gear drive, worm drive and so on. Shafting parts is those parts which are relative to shaft, and including shaft, antifriction bearing, sliding bearing, coupling and cluth. The parts which are not mentioned are defined as other parts, for instance, spring, box and so on. All in all, every large class contains several subcomponent, and these subcomponent can be divided into several small classes. For example, according to the differences about thread profile, screw joint can be split into triangular thread, rectangular thread, trapezoidal thread, saw-tooth thread and knuckle thread; keyed joint includes flat key joint, woodruff key joint, wedge key joint and tangential key joint. The content of machine design course is mainly about the operation principles, structural features, selection principles and the methods of parameter setting and physical design. On that basic, we can study design of whole system of machines and transmission system[1]. As a result of various universal parts, contend of course seems to be confusion. And every chapters focuses on different kinds of parts. So connection between chapter and chapter is absent which lead to the chaos of contend. In addition, there is not only basic knowledge, but also lots of practical knowledge in textbook. The way of mechanical design is not the only one, but there are usually multiple choices and methods. At the beginning, students cannot adjust to those conditions very quickly, so it is difficult for students to learn.

Although practicality of mechanical design is very obvious, basic principles and theories are undeniable foundation. In the basic concepts unclear circumstances, improvement of design capacity is meaningless. So the point is that students set the stage of mechanical design and develop their ability of design. In order to reach this goal, we should make types, application, operation principle and failure mode of parts as the focal points. In spite of conceptual problem, we should let students to grasp the meaning on the basis of understanding, rather than mechanical memorizing. And that is what let teachers have in-depth knowledge of contend of courses and be careful about lesson plan. In class, teaching contents should be vivid, 
visualized, and teacher should explains profound theories in simple language and combines engineering practice, makes interaction with students, focuses on key contents, get knowledge to be an organic thing through induction, compare and conclusion. On the aspect of teaching contend, we should pay attention on the combination of traditional teaching contend with new knowledge and modify those outdated contend, do reintegration of the system of courses, be creative in theory and ideally. Students will have a clear cognition on basic knowledge and construction of knowledge, on the basis of super section of the subject area, they can know the frontier and trend of this field.

\section{COMBINE WITH TECHNICAL PRACTICAL AND DEVELOP INTEREST ON LEARNING}

Although be based on practice, mechanical design is a theoretical model. So during the course of teaching, teacher should combine theory and practice together to improve students' understanding of courses. While explaining those principles and theories, teachers should list few of examples to guide students to think and enhance students' learning purposiveness.

In the teaching, appropriately, teachers should introduce some application examples and international newest research trend. If teachers do not learn new knowledge on time, teaching contend will not keep pace with the time, and then there will be some negative effects on students' interests. For timely knowing about current situation and development of mechanical design, teachers shoulder the burdens of updating teaching contend to make sure teaching contend suitable to foreign development trend. So get rid of teaching outline requirement, teachers should keep on learning and collecting new technology materials and introduce latest research results at home and broad to students in class optionally and purposefully. This can open students' horizon and at the same time, students will recognize relative research dynamic which be benefit for their current learn and future work. Adding the contend of research trend and newest research results can reflect some new knowledge, principles, methods and technology in teaching contend[2].

Moreover, introducing teachers' science results to students on class will not only deepen students' understanding on knowledge, expand their scope of knowledge, improve their interest in learning, and farther more, it can cultivate students' innovative thinking and science innovation consciousness.

\section{Multimedia Computer Assisted Teaching to IMPROVING TEACHING EFFECTIVENESS}

The teaching model of chalk and blackboard has been used till today and until now this is the main teaching model. The primary cause is that there is no way like this which is convenient for communication between students and teachers. But PPT lecture is so vivid that we have to combine both of traditional way and PPT to improve quality of teaching. After years of trying, single PPT or any other electronic course ware is denied by someone. But some topic about engineering practice is hardly to articulated only with writing on the blackboard and words which demands us join multimedia teaching contend within traditional methods. We can show those complex parts by multimedia which is vivid and easy for students to understand and strengthen the students' perceptual cognition and help student to overcome the difficulties about learning.

Besides, on-line education has become one of the most important teaching methods. So it is profound to perfect the system of Network-Assisted and take advantage of on-line teaching. Web-Based instruction should be complete and lively, contains the whole teaching contend and show those details which beyond description of traditional methods. Improving students' interests on study can make sure that they will study on-line in after-class time and in turn their interests will be improved again.

\section{STRENGTHENING EXPERIMENT AND TRAINING PRACTICE ABILITY}

We should change the situation that experimental teaching is subject to theoretical teaching which is a long-term phenomenon. We should make it clear that they closely tie to each other and there is no higher and lower which is the new period education concept. So we should pay lots of money on the reformation of experimental teaching including manpower and material resources.

First, there must be some experimental facilities which can meet the teaching requirement. The facilities should range from cognitive type, thinking type to creative type which make students to image the vast ocean of knowledges, to expand their horizon and improve their interests in learning and ability of creation. And the laboratory should be like a supermarket, opening to all students, so students can enjoy more freedom in studying, they will do some creative and designative experiments. According to their thinking, they will design the overall plan and experimental procedures which can give full play to students' activity and subjectivity. Allowing students to do experiment at any time and do creative analysis which makes lab to become the base of knowledge using and combining.

In order to improve students' creative thinking and ability and let students to know the process of designing and methods of detections. In the lab, we construct the test platform for mechanical behavior where provide all kinds of devices and needful parts, include different kinds of sensors and testers, rheostats, clutches, reducers and motors. And comprehensive experimental course for mechanical design is opened, concentrate those dispersive experiment together. Let students to try to grasp the kinds of test devices, their operating principle and the usage which can test mechanical behavior. Students also should learn the construction and installation of mechanical test platform, the methods of debugging of test-bed and experimental facilities. On those basis, students should start with design of experimental program and choice the experimental device, construct and build the test-bed, record and detect the experimental data on their own[3].

Because of expansion on the content of experimental teaching, we isolate experimental course from machine design course and form an independent course what can 
make content to be more abundant and students will pay more attention on experimental course. Years of practice proves that comprehensive experimental course of machine design really stirs up students interests, and let students to grasp of those experimental means to test machining parameters, and improve students' abilities of design experiment, practice and observation ability, and make sure that they are trained to be more skillful at management of experiment. Thus, the teaching method of regarding students as the main body and leading by teachers can bring out students' creative potentials [4].

\section{CONCLUSION}

Machine design mainly contains classroom instruction, experimental teaching and curriculum design. Every links supplement each other. So if we want to improve the whole quality of teaching, we must concentrate our effort on every links. We should make classroom instruction as the mainstay to lay the firm foundation of principle for students, combining experimental teaching and curriculum design and training students comprehensive abilities which can improve students' engineering quality and adopting to the community's need.

\section{REFERENCE}

[1] Lianggui Pu, Minggang Ji. Machine Design[M], China Machine Press, 2006

[2] Fang Tian, Xiuhong Zhang. Strengthening Practice to Enhance Comprehensive Abilities of Students [C]. Research in Teaching of Machine Design,2007

[3] Fang Tian, Xi Leng. Some Considerations on Teaching in Machine Design Course[C]. Research in Teaching of Machine Design,2008

[4] Shaohua Zhang. Modern Teaching Methodology in University [M], SSReader,2009 